Journal of

Back and

Musculoskeletal

Rehabilitation

Journal of Back and Musculoskeletal Rehabilitation 5 (1995) 187-188

\title{
Editorial
}

\section{Dancing medicine}

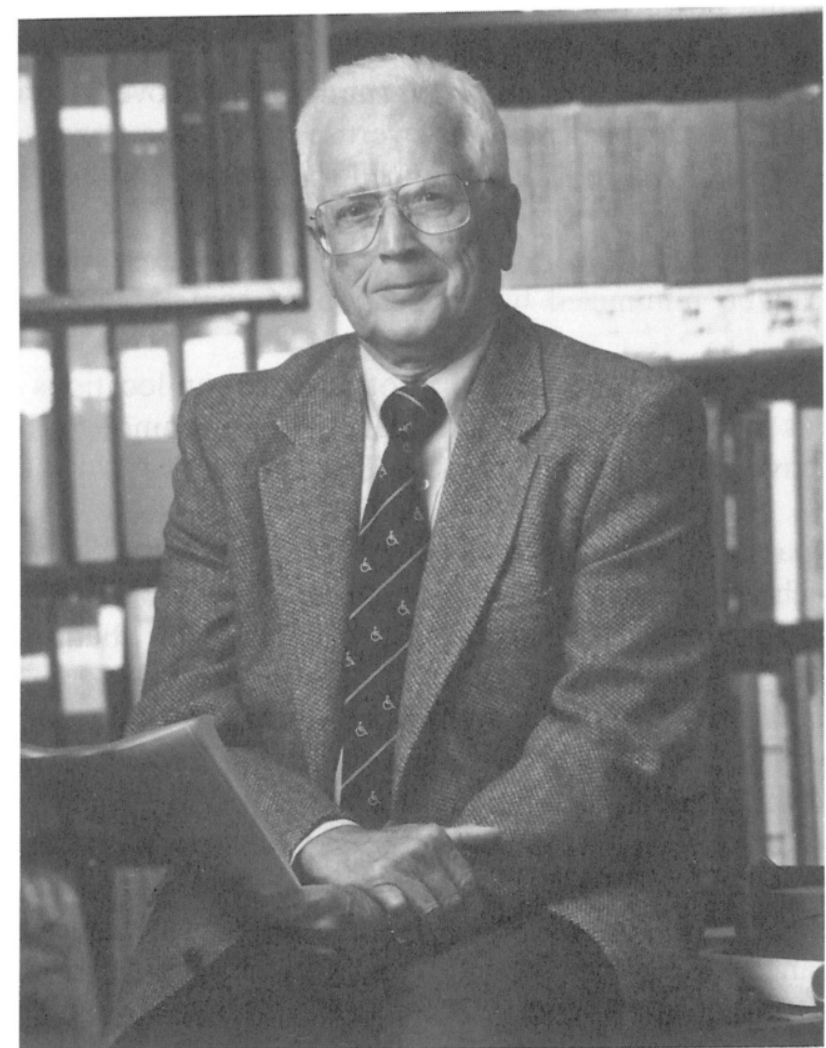

Ernest W. Johnson

Department of Physical Medicine and rehabilitation, The Ohio State University, 370 West 9 th avenue, Columbus, OH 43210-1238, USA

\section{No - not physicians prancing!}

This is that special area of medicine that diagnoses and treats dancers's injuries - both acute and chronic.

1053-8127/95/\$09.50 (C) 1995 Elsevier Science Ireland Ltd. All rights reserved. SSDI 1053-8127(94)00137-D 
My first experience occurred 15 years ago when I was confronted with practically an entire class of 1st year modern dance students with pains in their legs. I examined 13 young ladies who had been dancing barefoot for 3-4 weeks.

All had tenderness on the medial border of the tibia bilaterally ... a classic sign of shin splints. N.B. One must rule out stress fractures. But on physical examination, the tenderness extended over the middle one-third of the leg - not usually compatible with stress fracture.

In the anatomy laboratory, I localized the problem to enthesitis - a good word meaning inflammatory reaction of attachment of muscle or ligament to the periosteum - of the long toe flexors.

It's painful!

Shin splints have been used as a generic term to label any discomfort below the knee. However, to make it more specific, I suggest this term 'shin splints' be limited to describing aching pain in the middle one-third of the leg over the medial border of the tibia.

This is the attachment of the flexor digitorum longus - a site of enthesitis when the flexion of the toes is excessive and repetitive; as in the beginning of the dancing class in bare feet!

This is no different than similar complaints we see in runners who move from indoor to outdoor tracks - or even the reverse. Any change which requires overuse of the toe flexors can cause this pain. We have seen a couple of pole vaulters who only experienced shin splints on their 'push-off' leg.

How to treat?

In my opinion, it is best managed by continuing the activity or exercise but adding stretching and additional exercise. Pain can be minimized by application of something cold - either packs or ice massage - post-activity.

This is a similar approach to what I recommend at other common locations for enthesitis, e.g. tennis elbow, supraspinatus, gluteus medius 'tendinitis' and plantar fascitis, among others.

How does one provide active exercise to toe flexors? Try:

1. Separating the Sunday paper (or daily edition of the New York Times) into single sheets on the floor and then scrunching each into a small ball with the toes.

2. Dump 100 or so marbles onto the floor and use the toes to replace them in a jar.

But, now, back to the physiatrist and the dancer. There are clinics around the United States with a multidisciplinary approach for managing their acute and repetitive motion injuries. Physical and occupational therapy have much to offer for both relief and prevention.

I remember the Russian star of a ballet company touring Columbus who called after finding my name in the Yellow Pages. She requested that I provide her with $15 \mathrm{~min}$ of ultrasound to each medial calf prior to the evening performance. One of our senior physical therapists was delighted to contribute to an outstanding ballet performance.

When faced with plantar fascitis, shin splints, achilles tendinitis, knee and hip problems, as well as back problems .. seek help.

Rehab will usually oblige! 